\title{
2006-1637: WISCONSIN AND HAWAII WIT PARTNERSHIP TO ENCOURAGE WOMEN AND GIRLS IN RURAL AREAS TO PURSUE STEM FIELDS
}

Firouzeh Keshmiri, Milwaukee School of Engineering

Ann Bloor, Milwaukee School of Engineering

Mary Jo Wellenstein, Milwaukee School of Engineering

Mary Jo is counselor at Milwaukee School of Engineering (MSOE). She served as the director of MSOE's Women's Connections program for many years and has been instrumental in the successful use of MentorNet by MSOE female students. She is a champion for female students in their pursuit of an engineering degree. 


\title{
Wisconsin and Hawaii WIT Partnership to Encourage Women and Girls in Rural Areas to Pursue STEM Fields
}

\begin{abstract}
XXX in Milwaukee, Wis., is spearheading a new partnership with Hawaii's XXXX to encourage women and girls living in rural areas to enter into science, technology, engineering and math (STEM) fields. The partnership's mission is to:
\end{abstract}

- Ensure that women and girls, especially in rural areas, have more opportunities to be engaged in STEM careers.

- Develop program models that can be adopted in the future by local organizations and institutions

The Wisconsin and Hawaii Women in Technology projects are funded in part by the Cooperative State Research, Education, and Extension Service of the U.S. Department of Agriculture. Hawaii and Wisconsin are the only states that are involved in this program thus far.

Partnerships with industry, educational institutions, government agencies and youth-serving organizations are a key strategy for the WIT program. Other factors include proven outreach programs such as job shadowing, career days, science camps, and mentoring, along with apprenticeships and training designed to engage female students from middle school through college.

Mentoring has been identified as the most successful engagement strategy. WIT successfully negotiated with MentorNet, a Presidential award-winning online mentoring program that links undergraduate and graduate students with professionals in industry, government and high education. Through a WIT grant, students enrolled in Wisconsin universities will be able to participate in a proven, supportive, and effective retention program.

Through gender equity workshops, WIT offers tools to educators and industry to overcome the barriers that have created the chilly climate for women. The WIT project provides ongoing technical assistance to educators, guidance counselors, and industry partners on recruitment and retention skills to overcome these societal barriers.

The flagship Women in Technology Project was launched in 2000 by the XXXXX in Hawaii to help educate, support and retain local women as part of the STEM workforce. In Wisconsin, the WIT program is administered by XXXX.

This paper will describe the forming of the partnership and sharing of best practices between the two states. 


\section{Introduction}

US jobs are growing more rapidly in areas that require science, technology, engineering and math (STEM) knowledge and skills. A major shortage in skilled American workers threatens the ability to compete in the global marketplace. The number of American engineers is decreasing significantly and countries that traditionally have not graduated many engineers in the past, such as India and China, are now drawing significantly ahead of the United States. In the next 10 years, the United States will need 100,000 engineers and technicians per year. Yet the US educational institutions graduate only 60,000 engineers per year as compared with China, which is graduating 400,000 engineers per year. The decrease in the number of engineers, if unchecked, would eventually have a negative effect on the economy and the quality of life in the United States.

Currently, women represent $50.9 \%$ of the population (U.S. Census Bureau) yet only a small fraction of these women are working in STEM professions. A Science and Engineering Indicators Report issued by the National Science Foundation stated that in 1999, 1.2 million engineers in the labor force were male and only 183,000 were female (WEPAN). The reasons for this major discrepancy are many and include a lack of knowledge about engineering career opportunities prior to entering college, a lack of interest in math and science, and intimidation from both the classes, lack of female role models and the male-to-female ratio. Today women are underrepresented in science and engineering employment. This is due to their particularly low involvement in higher-level college science and mathematics courses and lack of information and a basic understanding of what engineers and scientists do. Studies show that every dollar appropriately invested in preparing the workforce yields four to five dollars in economic benefits to the nation. Gender equity is a key strategy for maintaining our Nation's preeminent status in science and technical innovation. The last 30 years have seen women make great strides in education and employment. Women are receiving more than 50 percent of the bachelors degrees conferred and are close to reaching parity in the once male-dominated fields such as law and medicine. Unfortunately, these gains have not been uniform across all fields. Women continue to be persistently underrepresented in high-demand, high-wage employment fields of science, technology, engineering, and math. While women make up nearly half of the American labor force in 2003-2004 (Bureau of Labor and Statistics), they are less than 34 percent of the total science and engineering workforce (1999 WEPAN). At a time when we face a shortage of skilled STEM workers who are U.S. citizens, women provide an untapped national resource to fill the workforce pipeline. Recent studies from the National Science Foundation and the Department of Commerce confirm these conclusions, including the September 2000 Report of the Congressional Commission on the Advancement of Women and Minorities in Science, Engineering and Technology, which concludes that "Unless the STEM labor market becomes more representative of the general U.S. workforce, the nation may likely face severe shortages in STEM works and thus risk undermining its global competitiveness."

Reaching women in rural communities is important as $31 \%$ of the nation's children are served in rural school systems. There is a dearth of research on girls and women in rural America in STEM fields. It is known that a mathematics achievement gap does not exist between rural vs. nonrural schools but at the state level a rural-nonrural mathematical achievement level does exist in over $40 \%$ states. This research states that the situation is attributed to structural features of the 
educational system, equity of local resources, the local culture of schooling, intentions of teachers and administrators, and adequacy of resources. As over more than one third of persons in female headed nonmetro families live in poverty it is essential that women pursue education and careers that provide them with more than a living wage to carry them through wage earning years and through retirement. Therefore, it is critical to develop a program to educate these young women about career possibilities in engineering, science and technical fields. A supportive community enables their return to their hometown to create a professional employment base. With STEM education young women would return to their rural communities with problem solving abilities and confidence in their technical skills. They will be equipped to deal with environmental issues, agricultural needs, manufacturing efforts, educational demands, and transportation requirements.

Women in Technology works to deliver best practices program models to Wisconsin's rural areas to ensure that women and girls have more opportunities to be engaged in science, technology, engineering and math education and careers. The Women in Technology program has partnered with industry, school systems, universities, youth serving and professional organizations to reach different levels of the rural community. An effective way to introduce science, technology, engineering and math to young women is by providing an opportunity for them to explore various aspects of the field through dynamic hands-on programs. Hands-on laboratories that explore "real life" experiences and social concerns have been shown to generate a great deal of enthusiasm for technical professions. Meeting and sharing exciting work with other females who are interested in math and science reduces isolation and increases excitement and confidence. This career path allows women to have salaries that provide for themselves and their families in their communities.

\section{Partnership and Goals}

XXX and XXX were awarded a grant from the Cooperative State Research, Education, and Extension Service of the US Department of Agriculture. This funding focuses on encouraging women and girls in rural areas into science, technology, engineering and math (STEM) fields. Communities with populations of 50,000 or less will be served.

The partnership's mission is to:

- Ensure that women and girls, especially in rural areas, have more opportunities to be engaged in STEM education and careers.

- Develop program models that can be adopted in the future by local organizations and other institutions

\section{Target Population}

Girls and women from the middle school through college have been targeted as recipients of this program to encourage them to enter the STEM pipeline and support them once they have entered the pipeline. A vast array of programs, trainings and awareness events are being developed for the following groups: 
- Middle school - instill interest in science and math

- High school - encourage girls to continue math \& science education, pursue STEM education in technical college and college

- Technical college - support women's science and math studies, encourage further education and job exploration

- University - support women's science and math studies, encourage further education and career planning

- Leaders/adults (program leaders, parents, guidance counselors, etc.) - teach them what they need to do to support girls in STEM education and careers.

\section{Current Activity}

The first phase of the effort was concentrated on developing relationships with organizations such as the Girl Scouts, community colleges, universities, industry, XXX alumni, professional women's organizations, etc. These relationships are important to the success of this program to recruit participants, increase awareness, and secure additional funding. A goal of the WIT program is to develop new leaders in the targeted region to sustain program activities after the grant funding has ended.

This institution is the local affiliate college for Project Lead the Way (PLTW). This national organization partners colleges and school districts to establish engineering courses in middle and high schools that have a special focus on recruiting young women. Project Lead the Way gives teachers the tools and confidence in teaching and explaining career applications of math and science. The high school program is a four year sequence of courses which, when combined with traditional mathematics and science courses in high school, introduces students to the scope, rigor and discipline of engineering prior to entering college. The approximate cost of the equipment for PLTW is between $\$ 70,000$ and $\$ 117,000$ plus the cost of teacher training. WIT is planning on helping new schools become PLTW certified by providing partial funding, help identify other sources of funding through other WIT relationships that are developed during the implementation of this grant and provide seed funding for development and implementation of recruitment plans of young women. More information about PLTW can be found at the following website http://www.pltw.org/aindex.htm.

Future Bound is a program developed in cooperation with the Wisconsin Technical College System to support females making transition from two-year technical college to a four-year university to complete an engineering bachelor's degree. One aspect of the program provides paid research experiences for the transferred students along with structured mentoring of these students to increase their success rate in their university.

A seed grant of $\$ 2000$ was provided to the University of Wisconsin- Sheboygan, a two-year campus, to host a Science and Engineering Day for high school girls. The keynote speaker was a female engineering alumnus who was raised in rural Wisconsin and returned to rural Wisconsin to pursue an engineering position. XXX's female engineering students designed and led three hands-on engineering activity sessions in addition to being part of a panel of engineering and science students. This program model will be utilized with other two-year university campuses 
as well as youth serving organizations. The seed grants focus on helping local universities and organizations develop programs and funding sources that can sustain such initiatives.

Four and two-year universities and technical colleges in Southeast Wisconsin have joined forces to host a tutoring conference for to teach university leaders and students how to appropriately tutor underrepresented populations. The thrust of the conference is to increase the retention rate of underrepresented populations pursing STEM degrees. Current students in STEM fields served as role models at this conference.

Wisconsin Girls Collaborative Project is an expansion of the Northwest Girls Collaborative Project (NWGCP), a program funded by National Science Foundation (NSF). This unique program focuses on developing a database of Wisconsin STEM programs and brings together organizations in Wisconsin that are committed to informing and motivating girls to pursue careers in STEM fields. The Wisconsin program is administered by the Wisconsin Department of Public Instruction. XXX was part of the initial planning meeting and has participated in the state-wide kickoff conference. In addition, XXX hosted a regional forum for southeastern organizations to network and discuss STEM programming. These meetings provide opportunities for educators, youth serving organizations, etc. to meet and discuss topics regarding women in STEM and hopefully develop partnerships for continued activity. More information on the Wisconsin Girls Collaborative Project can be found at the following website http://www.pugetsoundcenter.org/ngcp/nwgcp/index.html

Summer programs that help high school students explore career opportunities in Engineering have been a part of this campus for many years. Scholarships are provided to the interested and qualified female high school students living in rural areas to participate in a week long program. These programs provide real life experience about college living and technical careers.

Engineering and science badge programs have been developed with local Girl Scout organizations. Aerospace initiatives were developed earlier with funding from the Wisconsin Space Grant Consortium. Continuation and expansion will assist Girl Scout leaders provide STEM opportunities for Girl Scout troops. Work with Girl Scout councils will continue as an engineering and other STEM related badge programs are developed for middle school girls. XXX female engineering students designed, planned, and led events.

This grant provides funding to attend Women in Engineering Program and Advocates Network (WEPAN), American Society of Engineering Educators (ASEE) and Society of Women Engineers (SWE) conferences to share information and encourage others to adopt activities. Conference attendance is an important professional development opportunity especially for female engineering students. These meetings are also an opportunity to meet with Hawaii partners to discuss ongoing program issues

WIT successfully negotiated with MentorNet, a Presidential award-winning electronic mentoring program that links undergraduate and graduate students with professionals in industry, government and high education. Through the WIT grant, students enrolled in the University of Wisconsin system and the Wisconsin Technical College System (42 campuses) who meet 
MentorNet's qualifications are eligible to participate in a proven supportive and effective retention program.

\section{Future Activity}

Future activity includes developing adult/leader training to help parents and adults working with girls and women learn how to mentor, provide program and educational opportunities that encourage and sustain girl's interest in STEM, and help adults understand the important impact their leadership has on girls' interest in science and engineering. Second year plans include booths at county fairs staffed by professional female engineers and female engineering students. County fair booths will provide hand-on activities and materials to increase awareness of the need for females in STEM fields. Relationships will be developed with the 4-H organization with specific programs developed around GPS activity. The Department of Agriculture has developed a GPS youth program to interest children in technology. This program will be adapted to the needs and program interests of the local community. In addition, STEM career fairs will be organized in high schools and technical colleges utilizing engineering and science professionals from local organizations and industry.

\section{Evaluation}

Evaluation forms are completed by all program participants and reviewed by the WIT program team. Evaluation tools have been developed using materials from Assessing Women in Engineering (AWE). AWE Products were developed, validated and tested through a seven institution coalition as part of a 3-year project sponsored by the National Science Foundation (NSF) and Research on Gender in Science and Engineering (GSE). They have been developed specifically to determine the effectiveness of engineering programs geared towards girls and women. In addition, the WIT advisory committee meets twice a year to review and evaluate program activity.

\section{Sustainability}

The strategy for sustainability lies in the development of collaborations with organizations with similar goals, a sharing of strengths, resources and multiple funding sources. It is the intent of WIT to develop successful, diverse partnerships with local organizations with a strong knowledge of the community and local resources. Ownership of the program(s) at the local level is extremely important for sustainability. Utilizing XXX alumni working in local industry is a key to enlisting the financial support of industry that will depend on the professional development of girls for future economic stability. Facilitating relationships between female serving organizations, industry and universities is vital to maintaining the life of the programs. WIT will piggyback on existing programs such as school systems adopting Project Lead the Way. These school systems have already committed funding to this curriculum, have submitted proposals to the Kern Family Foundation for additional support and will rely on WIT for funding of the girls recruitment plan. In addition, work with grant writers at universities and fund development personnel at local organizations such as the Girl Scouts will ensure that funding is not based solely on one source of money. With the development of successful programs, strong assessment, and strong partnerships credibility will be developed to pursue further funding. 


\section{Conclusion}

The Women in Technology program is administered by XXX University, which has a strong history of preparing women for leadership roles in science, technology, engineering and math through engineering and science degrees, participation in undergraduate research programs and their innovative outreach programs in STEM. Exciting new paths are being developed to encourage girls in rural environments to pursue STEM education and careers. A supportive community enables the possibility of women returning to their hometown to create a professional employment base, thus improving the economic health of the rural areas. Young women will return with problem solving abilities and confidence as well as science, math, engineering, and technical skills to help their rural communities. They will be equipped to deal with environmental issues, agricultural needs, manufacturing organizations, educational institutions, and transportation needs. These careers will have a positive impact on the vitality of the rural communities.

\section{References}

AAUW Educational Foundation, Under the Microscope, Washington, D.C., March 2004

Andrews, Christine, L., McCum, Sharon, Wilkens, Leslie, Women in Technology (WIT): A Paradigm for Working Toward Systemic Change in Science, Technology, Engineering and Math (STEM) Education and Employment, IWPR 2003 Conference, Washington, D.C., June 2003

Beeson, Elizabeth, Strange, Marty, Why Rural Matters 2003: The Continuing Need for Every State to Take Action on Rural Education, Journal of Research in Rural Education, Spring 2003, Vo. 18, No. 1. 3-16

Congressional Commission on the Advancement of Women and Minorities in Science, Engineering and Technology Development, Land of Plenty: Diversity as America's Competitive Edge in Science, Engineering and Technology. Sept. 2000.

Howley, Craig B., Mathematics Achievement in Rural Schools, ERIC Digest, 2003, 1-8

National Science Foundation, Division of Science Resources Statistics, Women, Minorities, and Persons with Disabilities in Science and Engineering: 2004, NSF 04-317 (Arlington, VA, 2004)

National Science Foundation, Division of Research, Evaluation and Communication, Summary Report on the Impact Study of the National Science Foundation's Program for Women and Girls, NSF RED9452967, Arlington, VA December 2000

USDA, ERS, Rural America at a Glance, 2003, Sept. 2, 2003, http://www.ers.usda.gov/publications/rdrr97-1/lowres_rdrr97-1.pdf 